\title{
Antipsychotic-associated psoriatic rash - a case report
}

\author{
Camelia-Eugenia Bujor ${ }^{1}$, Torkel Vang ${ }^{2}$, Jimmi Nielsen ${ }^{1,2,3}$ and Ole Schjerning ${ }^{1,2^{*}}$ (D)
}

\begin{abstract}
Background: Antipsychotics are a heterogeneous group of drugs. Although, antipsychotics have been used for years, unexpected side effects may still occur. With this case report we focus on a possible association between psoriasis and antipsychotics.

Data on the patient's course of psychiatric disease, onset of psoriasis and its evolution were extracted from the patient's medical files.

Case presentation: We present a case of a 21-year-old female diagnosed with schizophrenia. She was initially treated with quetiapine, and later switched to aripiprazole due to weight gain. After initiation of antipsychotic treatment, the patient suffered from severe psoriasis lesions.
\end{abstract}

Conclusions: Antipsychotics may possess immunological properties that may be involved in immune-mediated conditions, such as psoriatic rash. Further studies are warranted to determine causality and mechanism.

Keywords: Aripiprazole, Quetiapine, Psoriasis, Side effects, Schizophrenia, Antipsychotic drugs, T cells, Cytokines

\section{Background}

Psoriasis, which affects up to $3 \%$ of the adult population, is a chronic inflammatory skin disease characterized by excessive growth and aberrant differentiation of keratinocytes. The etiology of psoriasis is incompletely understood but involves both genetic risk factors and environmental triggers. Genetic analyses have implicated genes associated with development/differentiation/function of immune cells but also genes important for epidermal differentiation and skin barrier function [1]. The recent introduction of biological agents as a treatment option for psoriasis has enhanced our knowledge of the pathogenesis of the disease. Interestingly, interleukin 12 (IL-12) / IL-23 antagonists have been demonstrated to be efficient anti-psoriatic drugs for patients with moderate to severe disease burden [2]. This suggests a role for $\mathrm{T}$ helper cells type 1 (Th1 cells, characterized by production of interferon $\gamma$ and tumor necrosis factor $\alpha$ ) and/or $\mathrm{T}$ helper cells type 17 (Th17 cells, characterized by secretion of IL-17A/F and IL-22) in the pathogenesis of psoriasis as the differentiation/stability of these cells are stimulated by IL-12 and

\footnotetext{
* Correspondence: o.schjerning@rn.dk

${ }^{1}$ Department of Psychiatry, Aalborg University Hospital, Aalborg, Denmark

${ }^{2}$ Department of Clinical Medicine, Aalborg University, Aalborg, Denmark

Full list of author information is available at the end of the article
}

IL-23, respectively. However, recent studies have indicated that both IL-23 antagonists and IL-17 antagonists are efficient anti-psoriatic drugs, suggesting that abnormalities in the IL-23/Th17 axis are of special importance in the pathogenesis of psoriasis [2].

Several factors are known to exacerbate psoriasis. These include traumatic injury to the skin, physical and psychological stress, cold weather, and excessive alcohol intake. Administration or withdrawal of certain drugs may also trigger psoriasis or exacerbate existing psoriasis. Especially, lithium, beta-blocking agents, carbamazepine, and sodium valproate have been associated with triggering or worsening of psoriatic rash [3]. Interestingly, all these drugs show immunomodulatory effects and as psoriasis clearly is an immune-mediated disease a common mechanism is most likely.

Antipsychotics, which remain the cornerstone in the treatment of schizophrenia and other psychoses, affect several organ systems beyond the central nervous system. Along these lines, immunomodulatory effects of antipsychotics have also been described [4]. With these effects in mind and with the aim to increase focus on this serious adverse effect, we present a case report with a patient developing psoriatic rash during antipsychotic treatment with quetiapine and aripiprazole. 


\section{Case presentation}

The patient is now a 21-year-old woman that was diagnosed with ICD-10 F20.0 paranoid schizophrenia at the age of 17. All psychiatric charts were reviewed to establish a comprehensive sequence of relevant medical events. The patient's general practitioner was contacted and all appointments regarding skin conditions were evaluated. The treating dermatologist was contacted as well and charts were reviewed.

The Patient have no diagnostically confirmed family history of psoriasis. At the age of two the patient had been seen twice by the general practitioner (GP) due to eczema on the eyelids and in the palm of her hands. At the age of five she had another contact with her GP concerning birthmarks and a plantar wart.

The medication history and medical events are summarized in Fig. 1. At the age of 17 she was admitted to a psychiatric children's ward for 3 months and diagnosed with schizophrenia. Thereafter, she was followed in a psychiatric outpatient clinic. In the following, the time of the diagnosis is referred to as $\mathrm{T}_{0}$. Antipsychotic treatment with quetiapine was initiated at $\mathrm{T}_{0}$. Routine blood monitoring was performed during treatment start-up and at regular basis afterwards. At $\mathrm{T}_{0}$ plus 2 months treatment with simvastatin was initiated due to dyslipidemia with elevated blood-cholesterol. In the following months the patient experienced unacceptable weight gain. According to the patient, she experienced the first psoriatic lesions about 2 months after the initiation of quetiapine. First contact with the GP concerning possible psoriasis was at $\mathrm{T}_{0}$ plus 4 months with an approximately $2 \mathrm{~cm}$ wide skin lesions on the left arm as well as lesions on both elbows and knees. Topical treatment with various agents including Daivobet gel, Locoid cream, and Xamiol gel was commenced by the GP but the psoriasis lesions worsened. At $\mathrm{T}_{0}$ plus 7 months, treatment with quetiapine was discontinued and aripiprazole was initiated at $5 \mathrm{mg} / \mathrm{d}$ and gradually increased to $15 \mathrm{mg} / \mathrm{d}$ within 2 months. At $\mathrm{T}_{0}$ plus 12 months treatment with melatonin was initiated due to insomnia. Melatonin was discontinued at $\mathrm{T}_{0}$ plus 20 months. At the same time, treatment with sertraline was initiated; the dosage was increased slowly up to $200 \mathrm{mg} / \mathrm{d}$ due to anxiety and mild to moderate depressive symptoms. Concomitantly, the dosage of aripiprazole was increased to $25 \mathrm{mg} / \mathrm{d}$. The patient had another contact with her GP, at $\mathrm{T}_{0}$ plus 25 and 28 months, concerning her psoriasis. At $\mathrm{T}_{0}$ plus 30 months the patient wished to discontinue all her pharmacologic treatment due to possible side effects of the treatment. She had experienced emesis and vomiting for several months and had been evaluated by a gastroenterologist without finding any satisfactory physical explanation for the symptoms. Her treating psychiatrist suspected that the gastric symptoms were caused by simvastatin, which was discontinued at $\mathrm{T}_{0}$ plus 30 months. However, the patient was convinced that sertraline and aripiprazole worsened her anxiety symptoms and psoriatic lesions. Therefore, sertraline was discontinued by the patient at $\mathrm{T}_{0}$ plus 30 months. The patient wished to discontinue aripiprazole as well, but due to the risk of psychotic relapse she agreed to slowly tapering of the drug, which

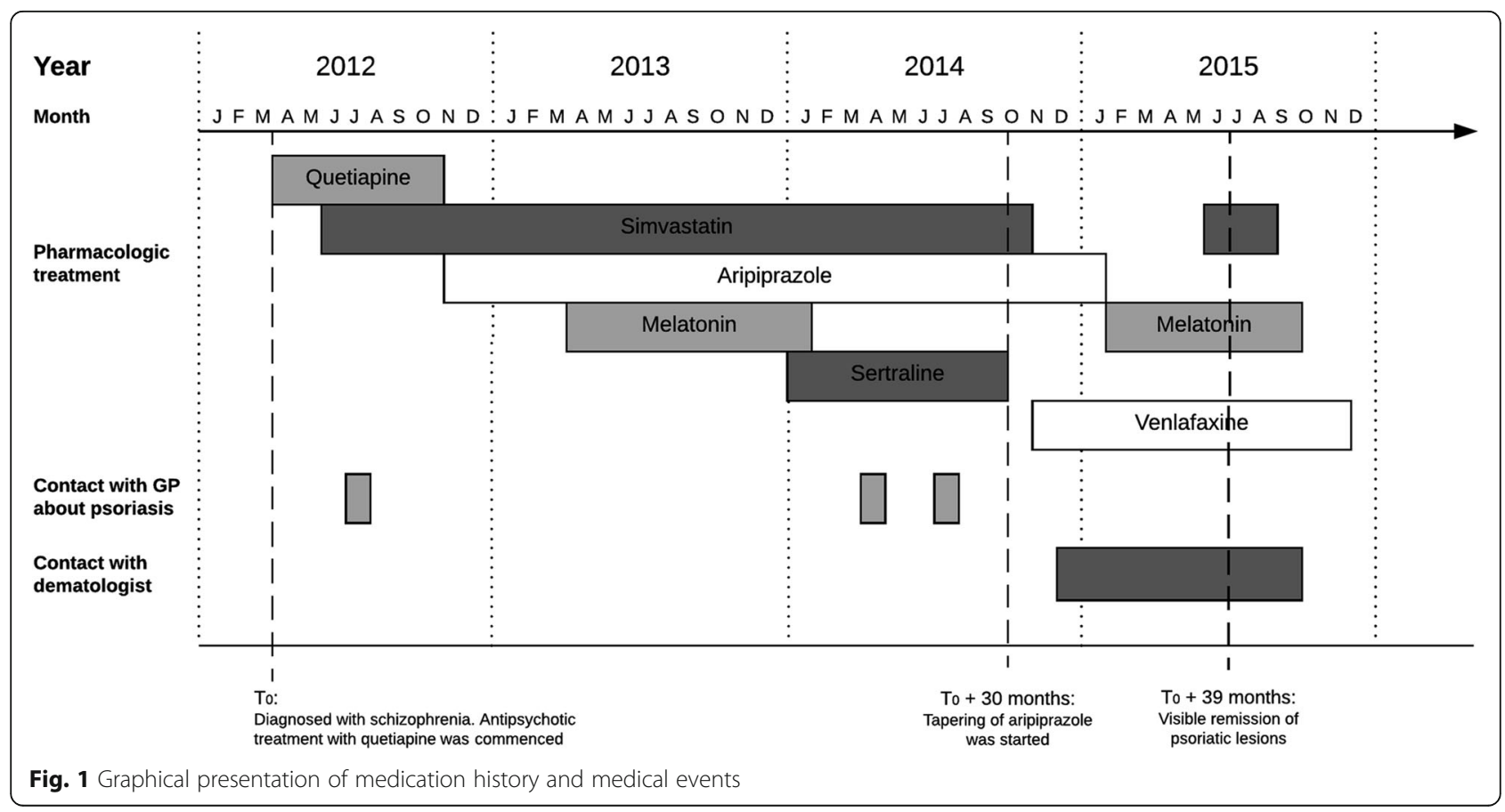


was discontinued at $\mathrm{T}_{0}$ plus 35 months. Due to ongoing anxiety and depressive symptoms treatment with venlafaxine was initiated at $\mathrm{T}_{0}$ plus 31 months. Due to the extensive worsening and lack of treatment results the patient was referred to a dermatologist at $T_{0}$ plus 32 months. Treatment with intensive phototherapy (UVB and Bucky rays) for 3 months gave only minor improvement, even when two more ointments (Diprosalic, Propiosalic) were added. Treatment with melatonin was resumed at $\mathrm{T}_{0}$ plus 34 moths and simvastatin was resumed at $\mathrm{T}_{0}$ plus 38 months.

At $\mathrm{T}_{0}$ plus 39 months, the psoriatic lesions had almost entirely disappeared without any modification of the previously commenced dermatological treatment. The recommenced treatment with simvastatin and melatonin did not worsen the psoriatic lesions in the following period. So far, the patient's psychiatric state has only been slightly affected by the discontinuation of aripiprazole (mild worsening of hallucinations). All blood tests were normal throughout the course of events.

\section{Discussion}

The most common agents involved in drug-associated psoriasis are beta-blockers, lithium, anti-malarials, anticonvulsants, and NSAIDs. Apart from olanzapine, there is a paucity of reports suggesting a possible link between the use of antipsychotics and psoriasis. To our knowledge, the current report is the first to describe a potential association between treatment with two other antipsychotics (quetiapine and aripiprazole) and psoriasis. However, a causal relationship cannot be established at this time since the pharmacological treatment of the patient was rather complex with several different drugs administered during the covered treatment period. Additional factors (both environmental and intrinsic to the patient) may also have affected the clinical course of the skin disease.

The exact mechanisms for drug-associated psoriasis are not known and most likely vary between different drugs. However, there seems to be some common features. These include a direct effect of the drug on keratinocytes as well as immunomodulatory properties of the drug. This also fits with the current view of psoriasis as a disease resulting from a complex interplay between environmental factors, keratinocytes, and components of both the innate and the adaptive immune system [5]. Beta-blockers represent a good example in this regard. Beta-adrenergic stimulation results in increased intracellular levels of cAMP in both keratinocytes and immune cells, leading to subsequent inhibition of cellular proliferation and for immune cells also reduced cellular activation [6-10]. With beta-blocking agents the opposite responses may occur; enhanced proliferation of keratinocytes and immune cells and augmented immune responses (i.e. a relative loss of immunological tolerance)
$[6,11,12]$. Likewise, lithium may stimulate keratinocyte proliferation, presumably through inhibition of glycogen synthase kinase 3 (GSK3), and also exerts immuneregulatory functions $[13,14]$. Moreover, all the above-listed drugs associated with psoriasis have been demonstrated to affect immune cells in various ways.

Several different drugs were prescribed to our patient, and they could all potentially have contributed to the subsequent development of psoriasis. To get a more objective evaluation, the Naranjo ADR scale [15] was applied for each drug administered. The score for quetiapine was 4 and, for simvastatin 3, for aripiprazole 2 and sertraline 2 . These scores suggest a "possible" association between the event (psoriasis) and the treatment. The scores for venlafaxine and melatonin were negligible $(0$ and -1 , respectively). A broader discussion on the role of quetiapine and aripiprazole is given below. Simvastatin as a contributing factor for the patient's psoriasis is less likely since the drug was discontinued and later reintroduced without affecting the clinical course of the skin disease. Furthermore, preclinical data indicate that statins favor stability of regulatory $\mathrm{T}$ cells (also known as Tregs, which inhibit conventional T cells) over conventional $\mathrm{T}$ cells. The net result may be increased immunological tolerance. In agreement with this, statins have been proposed as a potential treatment option in psoriasis and other immune-mediated diseases [16-18]. However, here it should also be mentioned that there are anecdotal reports linking certain statins (e.g. atorvarstatin) to psoriasis [19]. Regarding sertraline, it is an antidepressant drug belonging to the group of SSRIs (selective serotonin reuptake inhibitors), which are known to exert anti-inflammatory actions [20]. Sertraline has also been demonstrated to represent effective treatment in an animal model of rheumatoid arthritis [21]. Based on this, a link between sertraline and psoriasis seems less likely. Besides, there are no reports suggesting such a connection.

As already mentioned, the Naranjo ADR scores for quetiapine and aripiprazole indicated a "possible" association for a drug-induced event. The timing of the antipsychotics given to the patient (introduction of quetiapine at $\mathrm{T}_{0}$ and switch to aripiprazole at $\mathrm{T}_{0}$ plus 7 months) combined with the clinical course of the psoriasis (debut at $\mathrm{T}_{0}$ plus 4 , and remission at $\mathrm{T}_{0}$ plus 39 months) make it difficult to assess the individual roles of the two antipsychotics in the patient's skin disease. One possibility is that there is a class-effect, i.e. antipsychotics in general enhance the risk of psoriasis in susceptible patients.

We searched pubmed and embase for published case reports and case series implying an association between antipsychotics and development or worsening of psoriatic rash. We identified only two case reports [22, 23], covering a total of three patients. Summary of these case 


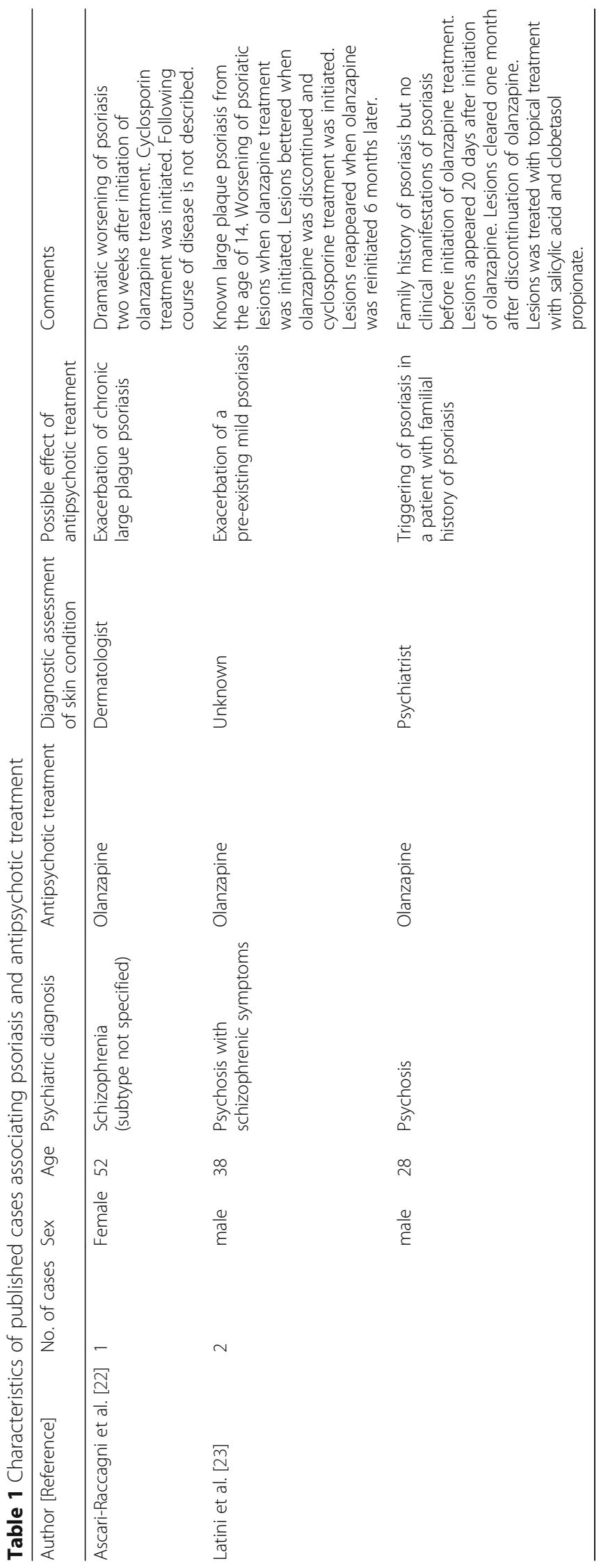


reports are shown in Table 1. All these patients experienced exacerbation of the skin disease while treated with olanzapine. Not all cases might have been identified in our search. Language was restricted to English, German, Dutch and Scandinavian language. Some review articles refer to cases concerning exacerbation of psoriasis during treatment with risperidone and quetiapine [24]. However, these cases were not published in journals indexed for medline or pubmed. These case reports should therefore be interpreted within their limitations. As the association between antipsychotics and psoriasis is not well established, psychiatrists may not have been aware of this potential association and a substantial underreporting may have occurred. In addition, we used search terms including only case reports indexed this way and not including patients from clinical studies.

Given dopamine's ability to bind to various dopamine receptors and thereby modulate cAMP levels in both keratinocytes and immune cells $[25,26]$, one hypothesis may be that antipsychotics through dopamine blockade can affect keratinocytes and/or immune cells, ultimately leading to psoriasis in predisposed individuals. The term "predisposed individuals" is important here since a casecontrol study using diagnostic and treatment data from general practice in Britain found reduced risk of psoriasis associated with the use of atypical antipsychotics, mainly accounted for by olanzapine [27]. In comparison, the same study clearly showed enhanced risk for psoriasis associated with lithium. Evidently, additional studies are required to clarify this issue. The typical debut of psoriasis is between 20 and 40 years of age. In the case described in this paper psoriasis may have developed coincidentally with the prescription of antipsychotic drugs or any other agents. Furthermore, psoriasis is generally considered to be a chronic disease where significant fluctuations of symptom severity can be seen over time, and the natural course of the disease may be rather unpredictable [28]. Therefore, the described clinical improvement experienced by the patient may have occurred independently of the drugs administered. There are also well-known triggering factors for psoriasis, e.g. infections and stress. Infections as a triggering factor in our patient were excluded on the basis of normal blood tests. Regarding stress, the patient's psychiatric condition got worse when she moved to another apartment located in an extremely noisy area; she experienced sleep disturbances as well as augmented paranoid delusions and high level of anxiety. This psychotic episode happened during treatment with aripiprazole and may also have affected the course of the skin disease.

Some studies have found increased risk of psychiatric disorders like anxiety and depression among patients with psoriasis [29-31]. Conversely, psoriasis is more prevalent among patients with schizophrenia [32]. The reason for the latter is not known, but it is tempting to speculate that the immune activation seen in connection with psychosis may play a role. In agreement with this, a recent study demonstrated constitutively enhanced levels of IL-23 in patients with schizophrenia [33]. As already mentioned, IL-23 plays an important role in the pathogenesis of psoriasis. Furthermore, both neuronal tissue and skin tissue are ectodermally derived and may share similar pathogenic pathways. Miyaoka et al. presented three cases where schizophrenia was associated with psoriasis [34]. Interestingly, they found that the exacerbation and remission of the skin manifestations of psoriasis closely correlated with the psychosis [34].

\section{Conclusions}

In summary, we report a possible association between treatment with antipsychotic drugs (quetiapine and aripiprazole) and psoriasis. Evidently, more studies are required to clarify if there is a causal relation and whether there is a class effect linked to antipsychotic drugs in general.

\section{Abbreviations}

ADR: Adverse drug reaction; GP: General practitioner; GSK3: Glycogen synthase kinase 3; IL: Interleukin; SSRI: Selective serotonin reuptake inhibitor; T: Time; Th: T helper cells; Tregs: Regulatory T cells

\section{Acknowledgements \\ Not applicable. \\ Funding \\ This research received no funding.}

Availability of data and materials

Not applicable.

Care checklist

We adhered to the CARE guidelines in the publication of this case report.

\section{Authors' contributions}

CB and OS collected data, interviewed the patient and wrote the case presentation. TV, JN and OS wrote the background and discussion sections. All authors contributed to the literature review and approved the final version of the manuscript. OS was the primary physician involved in the treatment of the patient.

Ethics approval and consent to participate Not applicable.

\section{Consent for publication \\ Consent to publish was obtained from the patient described in this case report.}

\section{Competing interests}

The authors declare that they have no competing interests.

\section{Publisher's Note}

Springer Nature remains neutral with regard to jurisdictional claims in published maps and institutional affiliations.

\section{Author details}

'Department of Psychiatry, Aalborg University Hospital, Aalborg, Denmark. ${ }^{2}$ Department of Clinical Medicine, Aalborg University, Aalborg, Denmark. ${ }^{3}$ Mental Health Centre Glostrup, University of Copenhagen, Copenhagen, Denmark. 
Received: 9 January 2017 Accepted: 29 June 2017

Published online: 04 July 2017

\section{References}

1. Roberson ED, Bowcock AM. Psoriasis genetics: breaking the barrier. Trends Genet. 2010;26(9):415-23.

2. Teng MW, Bowman EP, McElwee JJ, Smyth MJ, Casanova JL, Cooper AM, Cua DJ. IL-12 and IL-23 cytokines: from discovery to targeted therapies for immune-mediated inflammatory diseases. Nat Med. 2015;21(7):719-29.

3. Basavaraj $\mathrm{KH}$, Ashok NM, Rashmi R, Praveen TK. The role of drugs in the induction and/or exacerbation of psoriasis. Int J Dermatol. 2010;49(12):135161.

4. Polcwiartek C, Vang T, Bruhn CH, Hashemi N, Rosenzweig M, Nielsen J. Diabetic ketoacidosis in patients exposed to antipsychotics: a systematic literature review and analysis of Danish adverse drug event reports. Psychopharmacology (Berl). 2016;233(21-22):3663-72.

5. Nestle FO, Kaplan DH, Barker J. Psoriasis. N Engl J Med. 2009;361(5):496-509.

6. Sivamani RK, Lam ST, Isseroff RR. Beta adrenergic receptors in keratinocytes. Dermatol Clin. 2007;25(4):643-53. x

7. Nijhuis LE, Olivier BJ, Dhawan S, Hilbers FW, Boon L, Wolkers MC, Samsom $\mathrm{JN}$, de Jonge WJ. Adrenergic beta2 receptor activation stimulates antiinflammatory properties of dendritic cells in vitro. PLoS One. 2014;9(1): e85086

8. Vang T, Torgersen KM, Sundvold V, Saxena M, Levy FO, Skalhegg BS, Hansson V, Mustelin T, Tasken K. Activation of the $\mathrm{COOH}$-terminal Src kinase (Csk) by CAMP-dependent protein kinase inhibits signaling through the $T$ cell receptor. J Exp Med. 2001;193(4):497-507.

9. Vang T, Abrahamsen H, Myklebust S, Horejsi V, Tasken K. Combined spatial and enzymatic regulation of Csk by CAMP and protein kinase a inhibits $\mathrm{T}$ cell receptor signaling. J Biol Chem. 2003;278(20):17597-600.

10. Bauman GP, Bartik MM, Brooks WH, Roszman TL. Induction of CAMPdependent protein kinase (PKA) activity in T cells after stimulation of the prostaglandin E2 or the beta-adrenergic receptors: relationship between PKA activity and inhibition of anti-CD3 monoclonal antibody-induced T cell proliferation. Cell Immunol. 1994;158(1):182-94.

11. Klein M, Bopp T. Cyclic AMP represents a crucial component of Treg cellmediated immune regulation. Front Immunol. 2016;7:315.

12. Raker VK, Becker C, Steinbrink K. The CAMP pathway as therapeutic target in autoimmune and inflammatory diseases. Front Immunol. 2016;7:123.

13. Petersein C, Sack U, Mergl R, Schonherr J, Schmidt FM, Lichtblau N, Kirkby KC, Bauer K, Himmerich H. Impact of lithium alone and in combination with antidepressants on cytokine production in vitro. J Neural Transm (Vienna). 2015;122(1):109-22.

14. Hampton PJ, Jans R, Flockhart RJ, Parker G, Reynolds NJ. Lithium regulates keratinocyte proliferation via glycogen synthase kinase 3 and NFAT2 (nuclear factor of activated T cells 2). J Cell Physiol. 2012;227(4):1529-37.

15. Naranjo CA, Busto U, Sellers EM, Sandor P, Ruiz I, Roberts EA, Janecek E, Domecq C, Greenblatt DJ. A method for estimating the probability of adverse drug reactions. Clin Pharmacol Ther. 1981;30(2):239-45.

16. Mosiewicz J, Pietrzak A, Chodorowska G, Trojnar M, Szepietowski J, Reich K, Rizzo M. Rational for statin use in psoriatic patients. Arch Dermatol Res. 2013:305(6):467-72.

17. Steinman L. Development of therapies for autoimmune disease at Stanford: a tale of multiple shots and one goal. Immunol Res. 2014;58(2-3):307-14.

18. Weitz-Schmidt G, Welzenbach K, Brinkmann V, Kamata T, Kallen J, Bruns C, Cottens S, Takada Y, Hommel U. Statins selectively inhibit leukocyte function antigen-1 by binding to a novel regulatory integrin site. Nat Med. 2001;7(6): 687-92.

19. Cozzani E, Scaparro M, Parodi A. A case of psoriasis worsened by atorvastatin. J Dermatol Case Rep. 2009;3(4):60-1.

20. Nazimek K, Strobel S, Bryniarski P, Kozlowski M, Filipczak-Bryniarska I, Bryniarski K. The role of macrophages in anti-inflammatory activity of antidepressant drugs. Immunobiology. 2017;222(6):823-30.

21. Baharav E, Bar M, Taler M, Gil-Ad I, Karp L, Weinberger A, Weizman A. Immunomodulatory effect of sertraline in a rat model of rheumatoid arthritis. Neuroimmunomodulation. 2012;19(5):309-18.

22. Ascari-Raccagni A, Baldari U, Rossi E, Alessandrini F. Exacerbation of chronic large plaque psoriasis associated with Olanzepine therapy. J Eur Acad Dermatol Venereol. 2000;14(4):315-6.

23. Latini A, Carducci M. Psoriasis during therapy with olanzapine. Eur J Dermatol. 2003;13(4):404-5
24. Bliss SA, Warnock JK. Psychiatric medications: adverse cutaneous drug reactions. Clin Dermatol. 2013:31(1):101-9.

25. Fuziwara S, Suzuki A, Inoue K, Denda M. Dopamine D2-like receptor agonists accelerate barrier repair and inhibit the epidermal hyperplasia induced by barrier disruption. J Invest Dermatol. 2005;125(4):783-9.

26. Polcwiartek C, Vang T, Bruhn CH, Hashemi N, Rosenzweig M, Nielsen J. Diabetic ketoacidosis in patients exposed to antipsychotics: a systematic literature review and analysis of Danish adverse drug event reports. Psychopharmacology. 2016;233(21-22):3663-72.

27. Brauchli YB, Jick SS, Curtin F, Meier CR. Lithium, antipsychotics, and risk of psoriasis. J Clin Psychopharmacol. 2009;29(2):134-40.

28. Langley RG, Krueger GG, Griffiths CE. Psoriasis: epidemiology, clinical features, and quality of life. Ann Rheum Dis. 2005;64(Suppl 2):ii18-23. discussion ii24-15

29. Pompili M, Innamorati M, Trovarelli S, Narcisi A, Bellini S, Orsini D, Forte A Erbuto D, Botti E, Lamis DA, et al. Suicide risk and psychiatric comorbidity in patients with psoriasis. J Int Med Res. 2016:44(1 suppl):61-6.

30. Kurd SK, Troxel AB, Crits-Christoph P, Gelfand JM. The risk of depression, anxiety, and suicidality in patients with psoriasis: a population-based cohort study. Arch Dermatol. 2010;146(8):891-5.

31. Russo PA, Ilchef $R$, Cooper AJ. Psychiatric morbidity in psoriasis: a review. Australas J Dermatol. 2004:45(3):155-9. quiz 160-151

32. Chen SJ, Chao YL, Chen CY, Chang CM, Wu EC, Wu CS, Yeh HH, Chen CH, Tsai HJ. Prevalence of autoimmune diseases in in-patients with schizophrenia: nationwide population-based study. Br J Psychiatry. 2012; 200(5):374-80.

33. Borovcanin M, Jovanovic I, Dejanovic SD, Radosavljevic G, Arsenijevic N, Lukic ML. Increase systemic levels of IL-23 as a possible constitutive marker in schizophrenia. Psychoneuroendocrinology. 2015;56:143-7.

34. Miyaoka T, Seno H, Inagaki T, Ishino H, Ueda D, Ohno T, Dekio S. Schizophrenia associated with psoriasis vulgaris: three case reports. Schizophr Res. 2000;41(2):383-6.

\section{Submit your next manuscript to BioMed Central and we will help you at every step:}

- We accept pre-submission inquiries

- Our selector tool helps you to find the most relevant journal

- We provide round the clock customer support

- Convenient online submission

- Thorough peer review

- Inclusion in PubMed and all major indexing services

- Maximum visibility for your research

Submit your manuscript at www.biomedcentral.com/submit
) Biomed Central 